\title{
Exploiting the Second Coordination Sphere: Proteins as Host for Enantioselective Catalysis
}

\author{
Thomas R. Ward*, Jérôme Collot, Julieta Gradinaru, Andreas Loosli, Myriem Skander, Christophe \\ Letondor, Edith Joseph, and Gérard Klein
}

\begin{abstract}
With the aim of exploring the role of the second coordination sphere in enantioselective catalysis, achiral organometallic catalyst precursors are anchored in proteins via non-covalent interactions. A chemogenetic procedure allows the activity and the enantioselectivity of the artificial metalloenzymes to be optimized, to yield hybrid catalysts with features reminiscent both of enzymatic and homogeneous catalysts.
\end{abstract}

Keywords: Artificial metalloenzymes - Enantioselective catalysis · Second coordination sphere

The research theme of the Ward group is centered on the systematic exploration of the role of the second coordination sphere in catalysis. This approach is motivated by the fact that the role of the second coordination sphere is critical and often unpredictable in catalysis. Two examples suffice to illustrate our point:

i) In bioinorganic chemistry, very few model systems which reproduce the first coordination sphere of a metallo-coenzyme are as active and as selective as the true metalloenzyme where both the first- and the second coordination sphere have been optimized by evolution [1].

ii) In homogeneous catalysis, the role of the solvent and the counterion (typical second coordination sphere interactions) often play a determinant role in the performance of a catalyst [2][3].

\footnotetext{
${ }^{*}$ Correspondence: Prof. T.R. Ward Institute of Chemistry University of Neuchâtel Av. Bellevaux 51 Case Postale 2

In the field of homogeneous catalysis, the steric- and the electronic control of a catalytic moiety is primarily limited to the first coordination sphere of the metal. This contrasts with enzymes which take advantage both of the first- and the second coordination sphere to produce catalysts with exquisite activity and selectivity. In a biomimetic spirit, we incorporate active catalyst precursors in a protein environment to produce versatile artificial metalloenzymes.

Inspired by the seminal work of E.T. Kaiser [4], several groups have recently developed methods to covalently modify proteins by incorporating transition-metal catalysts to yield hybrid catalytic systems with promising properties [5-7]. The approach delineated herein relies on noncovalent interactions between the metal catalyst and the protein. As no chemical coupling step is required upon addition of the catalyst precursor to the protein, the integrity of the organometallic species is warranted [8]. As suggested by Whitesides [9][10], the biotin-avidin system offers an attractive scaffold to perform such experiments. The general concept is outlined in Fig. 1. A baseball mitt with a deep binding pocket epitomizes the concept of a protein providing a chiral environment for an organometallic catalyst precursor.

Such an approach offers several appealing features in terms of catalyst discovery and optimization:

i) The possibility of dissociating the activity (primarily dictated by the organo- metallic catalyst precursor) from the selectivity (governed by the host protein).

ii) The use of orthogonal diversity-generating procedures: molecular biology for the protein optimization as well as parallel synthesis for the organometallic fragment.

iii) A novel approach to exploit weak interactions (i.e. supramolecular) in enantioselective catalysis.

As host protein, we focus on avidin and related biotin-binding proteins. In the past decades, the biotin-avidin technology (often referred to as molecular velcro) has proven extremely versatile in various fields of biotechnology [11]. Indeed, it has been shown that derivatization of the valeric acid side chain of biotin does not significantly affect the remarkable affinity of biotin for avidin $\left(\mathrm{K}_{\mathrm{a}} c a \cdot 10^{14} \mathrm{M}^{-1}\right)$. Although most applications to date use a long spacer between biotin and the probe $\left(\mathrm{C}_{5}\right.$ or greater $)$, we reasoned that a short spacer (or no spacer at all) would ensure that the biotinylated catalyst precursor is located within the protein, providing a well-defined chiral environment for the enantiodiscrimination event. Although egg-white avidin is commercially available, its price is prohibitive for our research. We thus set up a molecular biology laboratory to produce large quantities of biotin-binding proteins [2]. With current molecular biological techniques, we are able to rapidly generate genetic diversity for the host protein either by site-directed or random mutagenesis. 


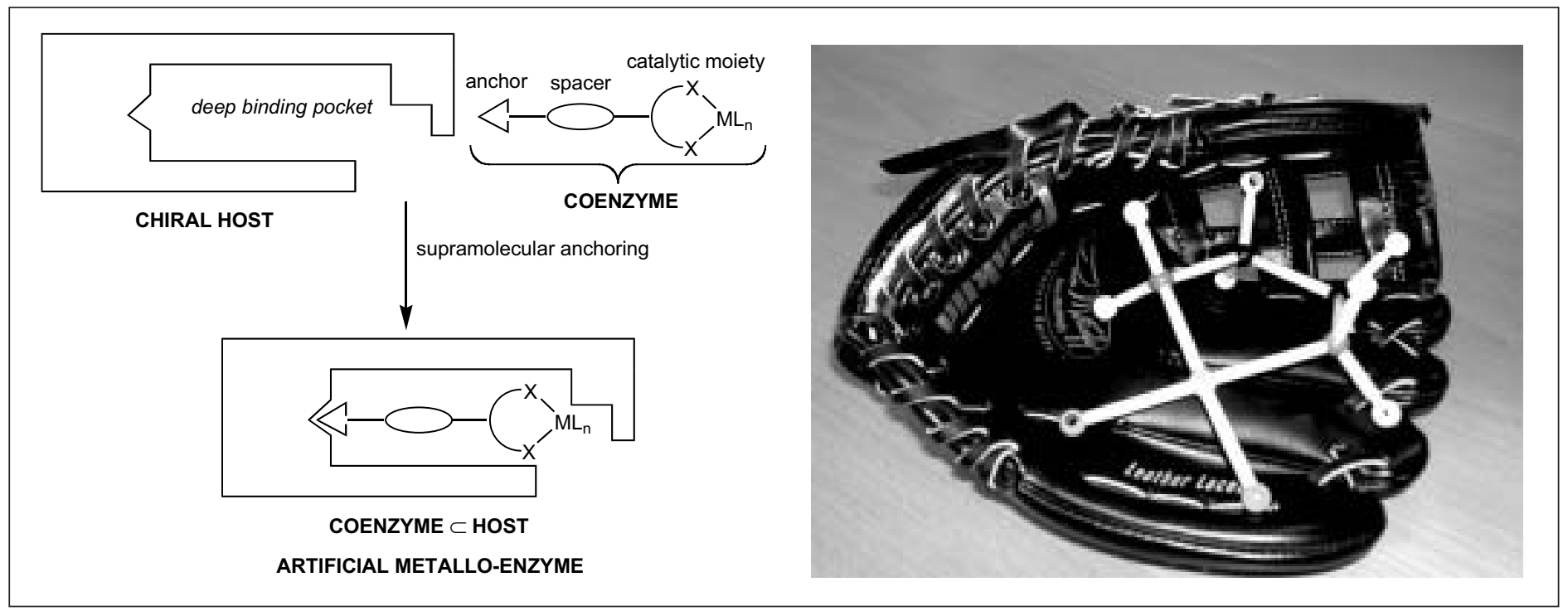

Fig. 1. Anchoring of an active achiral catalyst within a host protein with a deep binding pocket to produce enantioselective catalysts

Chemical diversity is achieved by varying the chelating ligand as well as by introduction of an amino-acid spacer between the biotin anchor and the organometallic moiety (Scheme 1). Such an approach, which relies on amide bond formation, allows the synthesis of small libraries of biotinylated catalyst precursors which have demonstrated activity, but produce essentially racemic product in the absence of host protein.

As a proof-of-concept, we studied the hydrogenation of $\mathrm{N}$-protected dehydroamino acids to produce enantioenriched $\mathrm{N}$-protected amino acids using biotinylated Rh-diphosphine catalyst precursors (Scheme 1). Although hydrogenases are known in nature, this reaction is prototypical of homogeneous catalysis. Hundreds of efficient systems exist for such enantioselective hydrogenation reactions in organic media [13]. In aqueous media however, much fewer systems have proven versatile [14].

Despite the power of combinatorial chemistry combined with molecular biological breeding techniques, the diversity space spanned by such hybrid catalysts is too large to be sampled efficiently by random modifications of either the organometallic catalyst or the host protein. We thus rely on statistical tools (clustering analysis, principal component analysis, design of experiment etc.) to design in silico experiments that sample more systematically the diversity space with a limited number of in vitro experiments. Our iterative procedure is sketched in Fig. 2.

Using the approach delineated above, we produced several efficient artificial met-

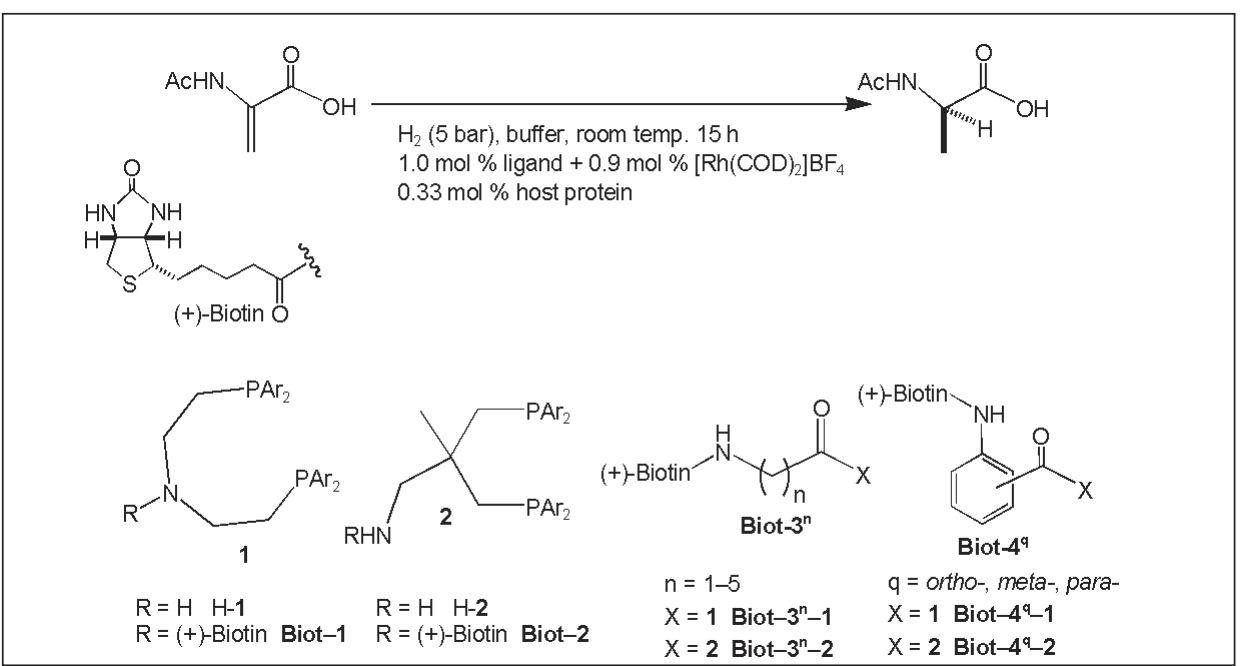

Scheme 1 . The enantioselective hydrogenation of acetamidoacrylic acid catalyzed by biotinylated rhodium-diphosphine complexes in (strept) avidin as host protein

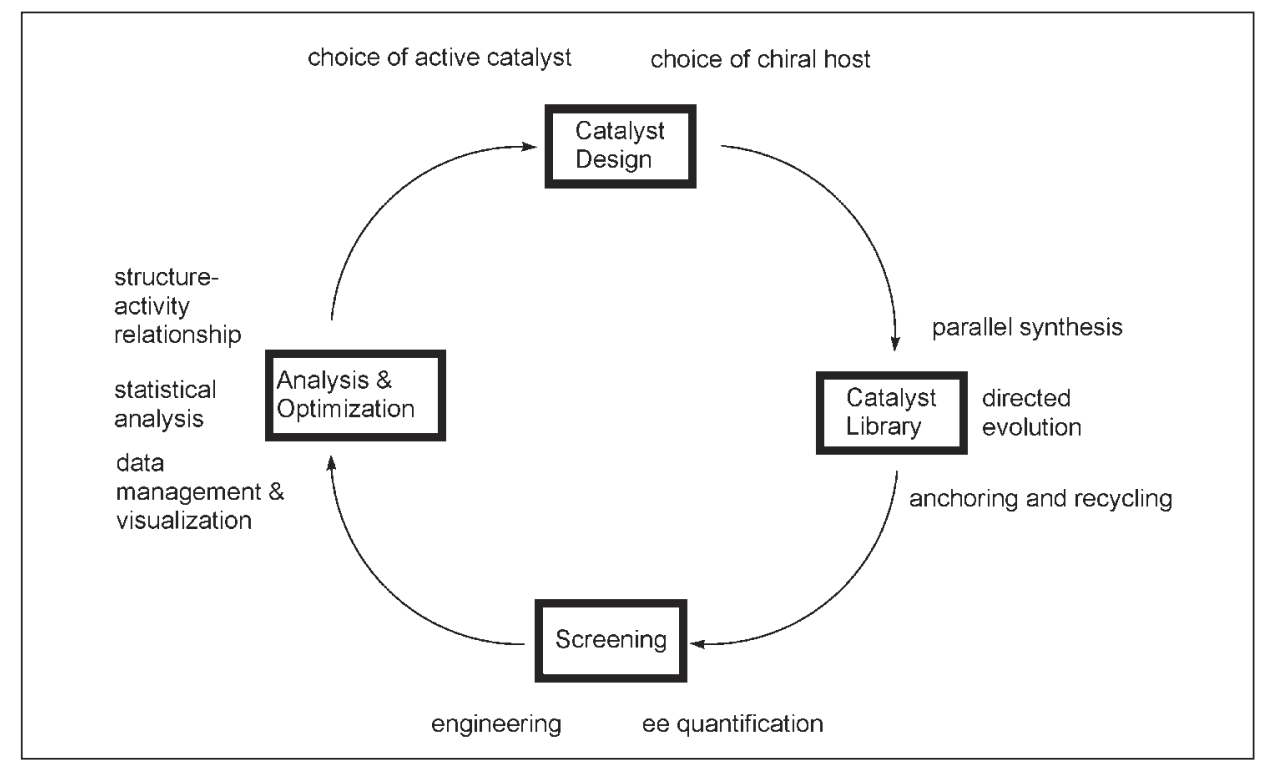

Fig. 2. Iterative procedure for the optimization of hybrid catalysts 
alloenzymes for the enantioselective hydrogenation of acylamidoacrylic (ee up to $96 \%$ ) and acylamidocinnamic acid (ee up to $88 \%$ ) [15][16]. In addition to varying the host protein, the spacer and the ligand skeleton, we showed that both the $\mathrm{pH}$ and the ionic strength of the buffered solution play a determinant role in the activity and the selectivity of the hybrid catalysts. As expected, the bottleneck of this screening procedure proved to be the ee quantification of the products, which was performed by GC analysis on a chiral column.

To circumvent this problem, we recently initiated a collaboration with Prof. Mioskowski to use competitive enzyme immunoassays (EIA) [17-20]. This powerful analytical method is based on the highly specific binding properties of antibodies which allow the direct measurement of the concentration of a given product in complex mixtures. By using an antibody that binds indiscriminately to the two enantiomers of the product (but not to the substrate), it is possible to determine the yield from the crude reaction mixture. Determination of the ee is then deduced by measuring the concentration of one of the enantiomer with an enantiospecific antibody.

The most interesting feature of having a rapid ee quantification for mandelic acid is the fact that this versatile assay can be used for three different reactions, as summarized in Scheme 2. Indeed, mandelic acid can be obtained either by $\mathrm{H}_{2}$ reduction or by transfer hydrogenation of phenylglyoxylate. Additionally, kinetic resolution by oxidation of racemic mandelic acid may afford enantioenriched mandelic acid which can be quantified with the same immunoassay.

To summarize, the approach delineated herein exploits the biotin-avidin technology to produce artificial metalloenzymes for enantioselective catalysis. These hybrid catalysts operate in aqueous medium, rely on second coordination sphere interactions for selectivity and can be optimized by mutagenesis. These features are reminiscent of enzymes. Further, we have shown that these hybrid catalysts display a broad substrate tolerance and can be fine-tuned by chemical means to produce both enantiomers of the product. These features are more reminiscent of homogeneous catalysts.

\section{Acknowledgements}

This work was supported by the Swiss National Science Foundation (Grants 62057866.99 and 4047-057532) as well as the Canton of Neuchâtel. J.C and J.G. contributed equally to this work. We thank Belovo Egg Science and Technology for a generous gift of egg white avidin.

Received: July 14, 2003<smiles>O=C(O)C(=O)c1ccccc1</smiles>

\section{transfer hydrogenation or}<smiles>O=C(O)C(O)c1ccccc1</smiles>

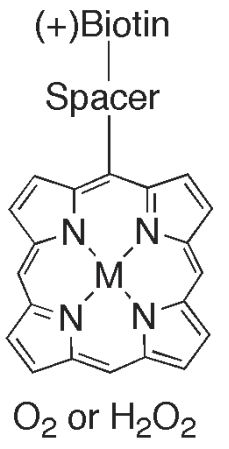

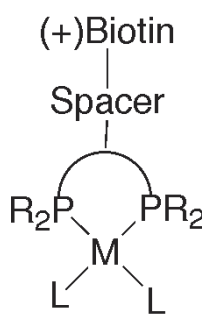<smiles>[10BH2]</smiles>

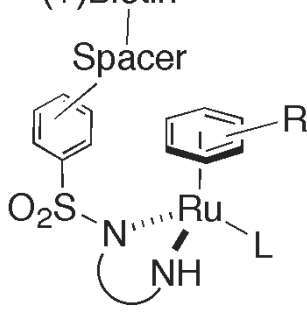

$\mathrm{H}_{2}$, pressure

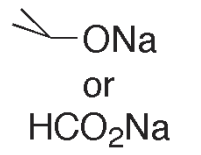

Scheme 2. An ee immunoassay for mandelic acid allows three different reactions to be screened efficiently

[1] R.H. Holm, P. Kennepohl, E.I. Solomon, Chem. Rev. 1996, 96, 2239.

[2] U. Burckhardt, M. Baumann, A. Togni, Tetrahedron Asym. 1997, 8, 155.

[3] D. Drago, P.S. Pregosin, A. Pfaltz, Chem. Commun. 2002, 286.

[4] E.T. Kaiser, D S. Lawrence, Science 1984, $226,505$.

[5] D. Qi, C.-M. Tann, D. Haring, M.D. Distefano, Chem. Rev. 2001, 101, 3081.

[6] M.T. Reetz, Tetrahedron 2002, 58, 6595.

[7] M.T. Reetz, M. Rentzsch, A. Pletsch, M. Maywald, Chimia 2002, 56, 721

[8] M. Ohashi, T. Koshiyama, T. Ueno, M. Yanase, H. Fujii, Y. Watanabe, Angew. Chem., Int. Ed. 2003, 42, 1005.

[9] M.E. Wilson, G.M. Whitesides, J. Am. Chem. Soc. 1978, 100, 306.

[10] C.-C. Lin, C.-W. Lin, A.S.C. Chan, Tetrahedron Asym. 1999, 10, 1887.

[11] M. Wilchek, E.A. Bayer, in 'Methods in Enzymology', Vol. 184, Academic Press, San Diego, 1990

[12] See the following article in this issue: A. Zocchi, N. Humbert, T. Berta, T.R. Ward, Chimia 2003, 57, 589 .

[13] E.N. Jacobsen, A. Pfaltz, H. Yamamoto, Eds., 'Comprehensive Asymmetric Catalysis', Springer, Berlin, 1999.

[14] D. Sinou, Adv. Synth. Catal. 2002, 344, 221.

[15] J. Collot, J. Gradinaru, M. Skander, N. Humbert, A. Zocchi, T.R. Ward, J. Am. Chem. Soc. 2003, 125, 9030.

[16] T.R. Ward, 'Protein Encapsulated Catalysts', German Patent Application, D10246740.4 .

[17] F. Taran, C. Gauchet, B. Mohar, S. Meunier, A. Valleix, P.Y. Renard, C. Créminon, J. Grassi, A. Wagner, C. Mioskowski, Angew. Chem., Int. Ed. 2002, 41, 124.
[18] O. Hofstetter, H. Hofstetter, V. Schurig, M Wilchek, B.S. Green, J. Am. Chem. Soc. 1998, 120, 3251.

[19] O. Hofstetter, H. Hofstetter, M. Wilchek, V. Schurig, B.S. Green, Nature Biotechnology 1999, 17, 371 .

[20] O. Hofstetter, H. Hofstetter, M. Wilchek, V. Schurig, B.S. Green, Chem. Commun. 2000, 158. 